\title{
Application of Next Generation Sequencing Technologies in Revealing Plant-Microbe Interactions
}

\section{Ramesh Kothari* ${ }^{1 *}$ Ravindra Pal Singh ${ }^{1}$ and Vishal Kothari ${ }^{2}$}

${ }^{1}$ Department of Biosciences, Saurashtra University, Rajkot-360005, Gujarat, India

${ }^{2}$ Department of Biotechnology, Junagadh Agricultural University, Junagadh, Gujarat, India

\begin{abstract}
Advancements in genomic (DNA and RNA) sequencing have dramatically accelerated research in the domain of host microbiome during current decade. Extensive application of next generation sequencing (NGS) technologies has identified the core microbiome of the human gut that is being used for improving health. Microbial communities of plant host have been recognized as a potential biological factor essential for shaping, acclimation, growth and health of the host. Nevertheless, we are far away to understand precise composition of the microbial communities and their function in the plant host. The purpose of this article is to highlight specific area of microbial - plant association that can be deeply analysed by using NGS and spectral technologies.
\end{abstract}

Keywords: Plant bacterial interaction; Next generation sequencing; Secondary genome; Quorum sensing; Associated bacteria

\section{Main Text}

Microbial communities associated with different parts of the plant make rhizospheric, phyllospheric and endospheric specific microbiome [1]. These communities influence health and development of plant by building of beneficial, neutral or detrimental association [2]. Majority of microbial communities do not interact with the host while some of them exert specific role in the plant health as well as its development $[3,4]$. For example, they are known to fix environmental nitrogen and produce various plant growth promoting substances. It has also been observed that associated bacterial communities employ quorum sensing (QS) system to communicate with plant host $[5,6]$. Homologous receptor of QS-LuxR system has been identified in several plant hosts that are responded to bacterial QS signaling molecule and subsequently modulating development of root and root structures [7]. The specific questions to understand host microbiome and their interaction are "what are the precise compositions of microbial communities in/on the host?" and "what are the core functional microbial communities of the host at given environmental conditions?" Addressing these questions is necessary to support plant growth and development in order to fulfil future consumption demand.

DNA (metagenomic), RNA (metatranscriptomics) and amino acid (metaproteomics) sequencing of metagenomic samples of the whole microbial communities of the host along with spectral analysis of their metabolites will be a prudent way to address above questions [8]. A study used the metagenomic study of rhizospheric samples from green house grow Lotus japonicus and determined that the plant had showed better growth in the presence of phytic acid and their rhizospheric microbiome consists of some gene clusters relating to phytic acid utilization, such as alkaline phosphatase and citrate synthase [9]. Another study has found that the rhizospheric microbial community is selected on the basis of functional cores genes related to the metabolisms of nitrogen, iron, phosphorus and potassium [10]. These genes are potential benefits of host, such as growth promotion and nutrition. Identification of potential genes has also been used to modulating plant health by transferring active beneficial microbiomes by mixing disease suppressive soils with disease conducive soils or alleviated drought stress in Arabidopsis thaliana [11,12]. A comparative study of metagenomics and metaproteomics study of rhizosphere and phyllosphere of rice plant revealed the complexity of microbial communities and certain genes are differentially expressed in both microbiomes [13]. Metatranscriptomics and metabolomics studies of the plant microbiome are powerful tools that can provide comprehensive picture of the active core microbiome of the host at given condition. Metatranscriptomics analysis of the rhizospheric microbiome of the Arabidopsis revealed several transcripts that were differentially expressed at different stages of the host. For example, disease suppression genes (streptomycin synthesis) were considerably induced at bolting and flowering stages [14].

Microbial metabolomics is the study of the set of metabolites present within microbial communities. By monitoring the global outcome of interactions of the complete set of metabolites of host microbial communities and their host can likely provide a more perfect picture of the actual physiological state of the microbiome. The dynamic metabolic flux of microbial communities and plant rhizosphere is extensively studied in context to rhizobial interaction [15]. Moreover, chemical interaction through bacterial QS (AHL) signaling molecule is recently highlighted due to their assessment in plant growth, development, and performance (Hartmann et al. 2014). LuxR solo receptors have been identified in both associated bacterial communities and plant host $[16,17]$. Bacterial LuxR solos are generally studied in pathogenic bacteria and rhizobia. In case of pathogenic bacteria, LuxR solos respond to plant produced unknown low-molecular weight compounds that induce pathogenicity related genes whereas in case of rhizobia, plant produced compounds modulate symbiosis island transfer and nodulation [15]. It is just beginning to understand interkingdom chemical communication of bacterial communities and their host and much information of this interaction remain unclear so far. Thus, the studying bacterial metabolites will pay the way to divulge this chemical communication with the perspective of controlling the disease and enhancing the growth of the host.

Definitely, the NGS technologies has revalorized our understanding

*Corresponding author: Ramesh Kothari, Department of Biosciences, Saurashtra University, Rajkot-360005, Gujarat, India, Tel: 912812586419; E-mail: kothari1971@gmail.com

Received April 06, 2016; Accepted April 09, 2016; Published April 12, 2016

Citation: Kothari R, Singh RP, Kothari V (2016) Application of Next Generation Sequencing Technologies in Revealing Plant-Microbe Interactions. Next Generat Sequenc \& Applic 3: e108. doi:10.4172/2469-9853.1000e108

Copyright: ( 2016 Kothari $R$, et al. This is an open-access article distributed under the terms of the Creative Commons Attribution License, which permits unrestricted use, distribution, and reproduction in any medium, provided the original author and source are credited. 
Citation: Kothari R, Singh RP, Kothari V (2016) Application of Next Generation Sequencing Technologies in Revealing Plant-Microbe Interactions. Next Generat Sequenc \& Applic 3: e108. doi:10.4172/2469-9853.1000e108

of microbial communities through provision of high through put sequencing at low cost, however, function of host microbiome is remain unclear. Thus, obtaining integrated information of microbial communities via different meta-omics technologies should be future goal to draw high-resolution regulatory maps of the activities and physiological potential of host microbiome. Such approach will lead to explain differentially expressed genes (stress, defense or climate change) of microbially mediated host process at given environmental condition. This information will be helpful for future perspective as a modulating microbiome for minimizing diseases incidence and enhancing gross plant productivity.

\section{Refernces}

1. Vorholt JA (2012) Microbial life in the phyllosphere. Nat Rev Microbiol 10: 828 840 .

2. Newton AC, Fitt BD, Atkins SD, Walters DR, Daniell TJ (2010) Pathogenesis, parasitism and mutualism in the trophic space of microbe-plant interactions. Trends in Microbiology 18: 365-373.

3. Zhan J, Sun Q (2012) Diversity of free-living nitrogen-fixing microorganisms in the rhizosphere and non-rhizosphere of pioneer plants growing on wastelands of copper mine tailings. Microbiological Research 167: 157-165.

4. Vacheron J, Desbrosses G, Bouffaud ML, Touraine B, Moënne-Loccoz Y, et al. (2013) Plant growth-promoting rhizobacteria and root system functioning. Front Plant Sci 4: 356

5. Ferluga S, Venturi $V(2009)$ OryR is a LuxR-family protein involved in interkingdom signaling between pathogenic Xanthomonas oryzae pv. oryzae and rice. J Bacteriol 191: 890-897.

6. Subramoni S, Venturi V (2009) PpoR is a conserved unpaired LuxR solo of Pseudomonas putida which binds $\mathrm{N}$-acyl homoserine lactones. BMC Microbiol 9: 125.
7. Bai XG, Todd CD, Desikan R, Yang YP, Hu XY (2012) N-3-oxo-decanoyl-Ihomoserine-lactone activates auxin-induced adventitious root formation via hydrogen peroxide- and nitric oxide-dependent cyclic GMP signaling in mung bean. Plant Physiol 158: 725-736.

8. Singh RP, Reddy CR (2015) Unraveling the Functions of the Macroalgal Microbiome. Frontiers in Microbiology 6: 1488

9. Unno Y, Shinano T (2013) Metagenomic analysis of the rhizosphere soil microbiome with respect to phytic acid utilization. Microbes and Environments 28: $120-127$.

10. Mendes LW, Kuramae EE, Navarrete AA, Van Veen JA, Tsai SM (2014) Taxonomical and functional microbial community selection in soybean rhizosphere. ISME J 8: 1577-1587.

11. Mendes R, Kruijt M, De Bruijn I, Dekkers E, Van Der Voort M, et al. (2011) Deciphering the rhizosphere microbiome for disease-suppressive bacteria Science 332: 1097-1100.

12. Zolla G, Badri DV, Bakker MG, Manter DK, Viyanco JM (2013) Soil microbiomes vary in their ability to confer drought tolerance to Arabidopsis. Applied Soil Ecology 68: 1-9.

13. Knief C, Delmotte N, Chaffron S, Stark M, Innerebner G, et al. (2012) Metaproteogenomic analysis of microbial communities in the phyllosphere and rhizosphere of rice. Isme Journal 6: 1378-1390.

14. Chaparro JM, Badri DV, nVivanco JM (2014) Rhizosphere microbiome assemblage is affected by plant development. Isme Journal 8: 790-803.

15. Venturi V, Fuqua C (2013) Chemical signaling between plants and plantpathogenic bacteria. Annu Rev Phytopathol 51: 17-37.

16. Patel HK, Suárez-Moreno ZR, Degrassi G, Subramoni S, González JF, et al. (2013) Bacterial LuxR solos have evolved to respond to different molecules including signals from plants. Front Plant Sci 4: 447.

17. Subramoni S, Florez Salcedo DV, Suarez-Moreno ZR (2015) A bioinformatic survey of distribution, conservation, and probable functions of LuxR solo regulators in bacteria. Front Cell Infect Microbiol 5: 16. 